J. Lake Sci. (湖泊科学), $2007, \mathbf{1 9}(4): 382-389$

http://www. jlakes. org. E-mail: jlakes@ niglas. ac.cn

(c) 2007 by Journal of Lake Sciences

\title{
湖泊氮素生物地球化学循环及微生物的作用“
}

\author{
曾 巾 $^{1}$, 杨柳燕 ${ }^{1 * *}$, 肖 琳 ${ }^{1}$, 尹大强 ${ }^{1}$, 秦伯强 ${ }^{2}$ \\ ( 1 : 污染控制与资源化研究国家重点实验室,南京大学环境学院, 南京 210093) \\ (2:中国科学院南京地理与湖泊研究所,南京 210008)
}

摘 要: 氮素是影响湖泊富营养化的关键元素之一, 对湖泊中氮素生物地球化学循环整个过程进行全面的了解, 有利于对 湖泊富营养化进行控制和治理. 本文综述了湖泊生态系统 (特别是富营养化湖泊) 中氮素的输人、输出及其在沉积物 - 水 界面的迁移转化规律, 着重分析和比较了藻型湖泊和草型湖泊的不同食物链中的氮素营养循环过程, 重点讨论了微生物 参与的硝化作用、反硝化作用、生物固氮和戻氧氨氧化等过程的最新研究进展, 并对氮循环相关的研究方法和技术进行了 小结. 最后指出当前国内外研究中函待解决的问题,并对湖泊氮循环今后的研究方向提出了建议.

关键词: 湖泊;氮素;生物地球化学循环;微生物

\section{Biogeochemical cycling of nitrogen in lakes and the role of microorganisms in conversion of nitrogen compounds}

ZENG $\operatorname{Jin}^{1}$, YANG Liuyan ${ }^{1 * *}$, XIAO Lin $^{1}$, YIN Daqiang ${ }^{1} \&$ QIN Boqiang ${ }^{2}$

(1: State Key Laboratory of Pollution Control and Resource Reuse, School of the Environment, Nanjing University, Nanjing 210093, P. R. China)

(2:Nanjing Institute of Geography and Limnology,Chinese Academy of Sciences, Nanjing 210008,P. R. China)

\begin{abstract}
It is generally considered that nitrogen is one of the major factors regulating the trophic status of lakes, and the biogeochemical cycling of nitrogen serves the most important function in lake systems. Lakes often receive large anthropogenic inputs of nitrogen that cause eutrophication, and the exchange of nitrogen-compounds between sediment and water has a profound effect in all kinds of lakes. Such increased nutrient loading promotes the growth of phytoplankton while rooted plants and benthic are suppressed due to reduced light availability, the transfer of the nitrogen through the food chains in algal lake and macrophytic lake is different accordingly. Meanwhile, in this review progresses made on the processes such as nitrification, denitrification, nitrogen fixation and anammox ( anaerobic ammonium oxidation) are emphasized. Methods and techniques applied in the research of biogeochemical cycling of nitrogen are also summarized, and the development of molecular techniques has contributed enormously to the rapid recent progress in the field. Current insufficiencies are pointed out and future directions are recommended in the end.
\end{abstract}

Keywords : Lake; nitrogen ; biogeochemical cycling; microorganisms

氮素 $(\mathrm{N})$ 是生命活动所需的基本营养元素, 也是引发水体富营养化的关键元素之一 ${ }^{[1]}$. 在世界上很多 国家, 由于人类活动导致大量氮素进人湖泊, 从而影响了湖泊的营养水平. 目前, 湖泊富营养化已成为我国 最重要的环境问题之一 ${ }^{[2]}$.

氮素的生物地球化学循环是整个生物圈物质能量循环的重要组成部分,在湖泊营养循环中占有重要地

“973”项目湖泊富营养化过程与蓝藻水华暴发机理研究 (2002CB412307) 和国家重大水环境专项 (2002AA601011) 共同资助. 2006-06-22 收稿;2006-11-02 收修改稿. 曾巾,女, 1982 年生, 硕士研究生; E-mail: zengjin1210@ gmail. com.

** 通讯联系人;E-mail:yangly@ nju. edu.cn. 
位. 对湖泊中氮素的生物地球化学循环整个过程进行全面的了解, 对其生态意义有足够的认识, 有利于对 湖泊富营养化进行控制和治理, 也可为氮循环理论研究提供新的视角. 鉴于此, 本文对湖泊生态系统中氮 素的生物地球化学循环整个过程进行综述, 对相关方面的最新进展进行总结, 并指出当前研究中存在的不 足, 以期对进一步深人研究起到一定指导作用.

\section{1 湖泊生态系统中氮素的生物地球化学循环}

氮素在湖泊生态系统内的循环是开放循环,如图 1 所示. 湖泊中各种无机氮,包括来源于地表水、大气 中的铵盐 $\left(\mathrm{NH}_{4}^{+}\right)$和硝酸盐 $\left(\mathrm{NO}_{3}^{-}\right)$等, 可在不同含氧层中进行硝化作用、反硝化作用等过程. 硝化作用和反 硝化作用都能产生亚硝酸盐 $\left(\mathrm{NO}_{2}^{-}\right)$; 不同来源的 $\mathrm{NO}_{2}^{-}$可参与硝化、反硝化、厌氧氨氧化. $\mathrm{NO}_{3}^{-} 、 \mathrm{NO}_{2}^{-} 、 \mathrm{NH}_{4}^{+}$ 等溶解态无机氮 (DIN) 和部分有机氮 ( Org-N) 以及大气中 $\mathrm{N}_{2}$ 等氮素都能被湖泊中特定的生物同化吸收; 生 物死亡分解后以 $\mathrm{Org}-\mathrm{N}$ 或 $\mathrm{NH}_{4}^{+}$形式存在. 水体中各种 $\mathrm{Org}-\mathrm{N}$ 和 $\mathrm{NH}_{4}^{+}$可以扩散和沉降进人沉积物, 成为湖泊 内源氮. 在沉积物中, $\mathrm{Org}-\mathrm{N}$ 一部分被重矿化为 $\mathrm{NH}_{4}^{+}$, 另一部分成为 $\mathrm{Org}-\mathrm{N}$ 汇. 总之, 氮素在湖泊中迁移和 转化是相互影响、相互关联的生物化学过程的集合, 所有过程形成了网状生态结构 ${ }^{[3-5]}$.

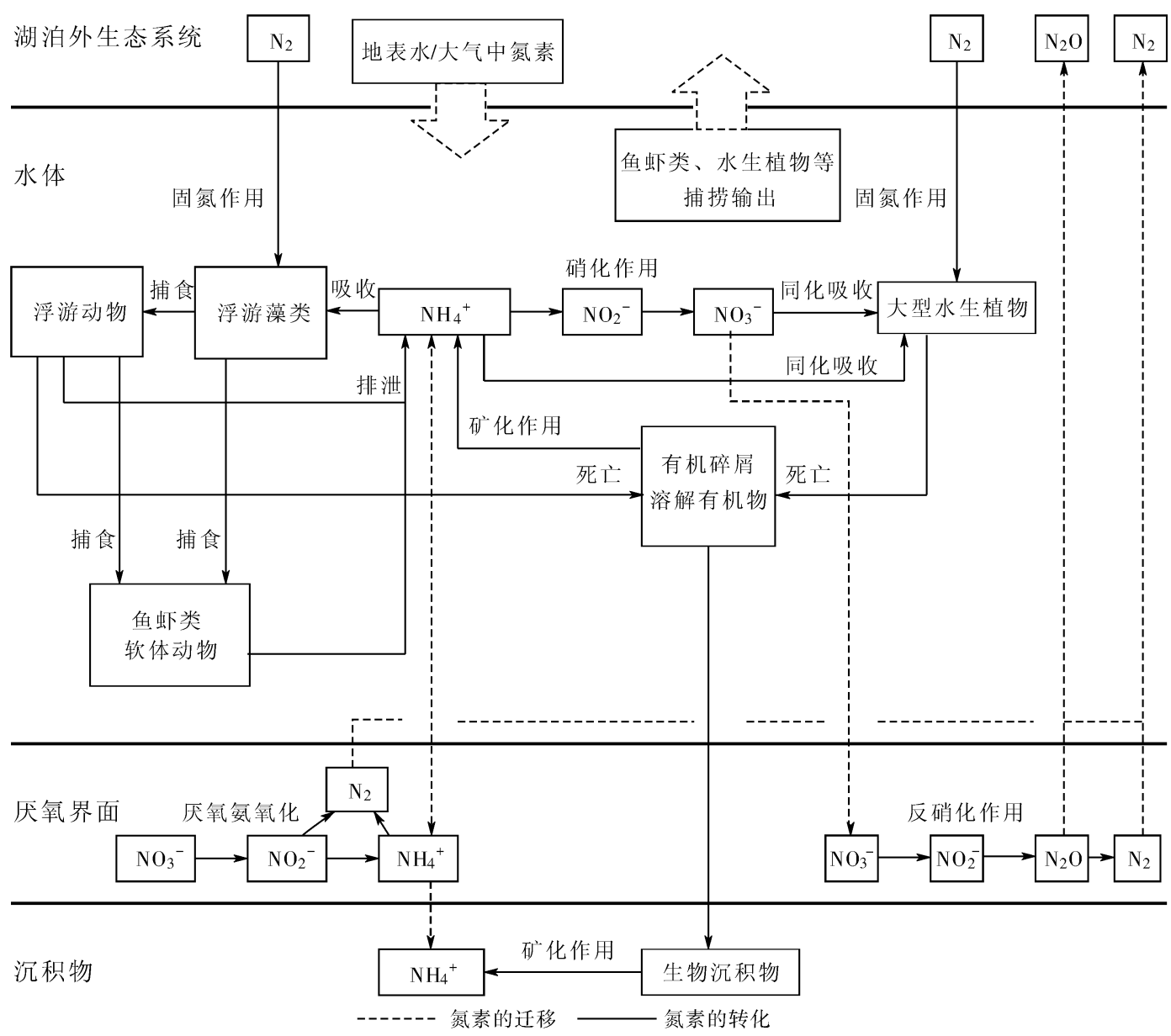

图 1 湖泊生态系统中氮素的生物地球化学循环示意图

Fig. 1 Conceptual diagram of major features of the biogeochemical cycling of nitrogen in the lake 


\section{1 湖泊氮素的输入与输出}

湖泊水体中氮素来源较多 ${ }^{[6]}$, 可概括为点源、面源和内源, 已有较多文献进行了相关报道 ${ }^{[7-10]}$.

湖泊生态系统中氮素的输出方式有三种. 首先, 藻类、高等水生植物、底栖动物等将氮素转化为自身生 物量, 经人工捞取或收获后离开湖泊生态系统. 其次, 氮素以气体 (如 $\mathrm{N}_{2} \mathrm{O} 、 \mathrm{~N}_{2}$ 等) 形式退出湖泊系统. 再 次,氮素通过沉积作用进入沉积物并固定下来.

\section{2 氮素在沉积物 - 水界面的交换}

氮素在沉积物 - 水界面的交换是水体中氮素迁移转化的主要过程之一,对湖泊的营养状态和水质都有 重要影响. 进人沉积物的氮素主要是有机氮, 它在沉积物中的浓度主要依赖于初级生产力, 并和有机碳 $(\mathrm{Org}-\mathrm{C})$ 强烈相关. 沉积物中释放的氮素首先进人间隙水中,再进一步扩散到水土界面和上覆水体中,扩散 动力来自于扩散面上的浓度梯度 ${ }^{[11]}$. 氮素主要以 $\mathrm{NH}_{4}^{+}$形式释放 (来源于含氮有机物的降解), 释放的 $\mathrm{NH}_{4}^{+}$ 在有氧情况下被迅速氧化成为 $\mathrm{NO}_{2}^{-}$和 $\mathrm{NO}_{3}^{-}$. $\mathrm{NO}_{2}^{-}$和 $\mathrm{NO}_{3}^{-}$在沉积物间隙水中的含量很低, 它们大多数通过 反硝化作用转化为 $\mathrm{N}_{2}$ (特别是在 $\mathrm{O}_{2}$ 浓度趋于零的沉积物层中) 或者通过异化还原为 $\mathrm{NH}_{4}^{+}$而释放 ${ }^{[12]}$.

氮素在沉积物 - 水界面的交换被物理 - 化学因素以及生物过程所控制. 氮素的释放取决于含氮化合 物分解的难易程度, 主要与 $\mathrm{O}_{2}$ 含量、氧化还原电位 $(\mathrm{ORP})$ 、沉积物中 $\mathrm{C} / \mathrm{N}$ 比值、阳离子交换量 $(\mathrm{CEC})$ 、温度 以及水动力条件有关 ${ }^{[11,12]}$. 底栖动物的排泄以及生物摚动行为、微生物的硝化作用和反硝化作用等过程也 影响沉积物 - 水界面的氮素物质动力学 ${ }^{[13]}$.

\section{3 氮素在湖泊生态系统食物链中的迁移转化}

湖泊中的动物、植物、微生物等构成湖泊生态系统的食物链, 各种生物通过同化吸收或选择性捕食, 使 得氮素在营养级中自下而上进行传递.

藻型湖泊生态系统中, 浮游藻类占优势地位, 大型水生植物以及鱼虾类遭到破坏 (图 1). 从理论上讲, 浮游植物首先利用的氮素是 $\mathrm{NH}_{4}^{+}$, 只有当 $\mathrm{NH}_{4}^{+}$不能满足需求时,浮游植物才会利用其它形式氮素( 如尿素 和 $\left.\mathrm{NO}_{3}^{-}\right)$; 蓝藻藻华暴发时, DIN 、尿素和分子态氮 $\left(\mathrm{N}_{2}\right)$ 同时被浮游植物利用 ${ }^{[14]}$. 死亡的浮游植物可被细菌 和浮游动物重矿化; 或者自溶产生溶解性有机氮 ( DON), 再被细菌降解为 $\mathrm{NH}_{4}^{+}$. 浮游植物中蛋白质含量 高, $\mathrm{C} / \mathrm{N}$ 比值约为 10 , 为降解蛋白质的细菌和浮游动物提供能量, 便于 $\mathrm{Org}-\mathrm{N}$ 进行矿化. 细胞膜的透过性使 得溶解物质能够释放, 因此自溶过程与细胞膜透过性相关, 死亡藻类的细胞在几天之内就迅速释放出蛋白 质. 藻类位于沉积物上表层, 沉积物中释放的 $\mathrm{NH}_{4}^{+}$在被氧化成为 $\mathrm{NO}_{3}^{-}$之前就被藻类吸收 ${ }^{[12]}$, 这可能是藻 型湖泊中 $\mathrm{NO}_{3}^{-}$浓度相对较低的原因. 浮游动物的捕食行为能够控制可食性藻类的生物量, 也能刺激非食用 性藻类的生长从而使其成为优势种 ${ }^{[15]}$. 富营养化湖泊的优势浮游藻类为食用价值比较低的蓝藻, 所以正 常的食物链遭到破坏, 湖泊生态系统的氮营养物质循环发生改变.

湖泊处于草型清水状态时,湖泊生态系统具有完整的食物链结构 (图 1). 大型水生植物通过自身对氮 营养元素的吸收同化、收获输出、沉积输出等过程, 使氮素脱离湖泊内的营养循环, 进人地球化学循环过程. 大型水生植物吸收利用 $\mathrm{NO}_{3}^{-}$但是易受高浓度 $\mathrm{NH}_{4}^{+}$的毒害. $\mathrm{NO}_{3}^{-}$被吸收转化为 $\mathrm{Org}-\mathrm{N}$, 这个过程需要光能. 在富营养化湖泊中, 大型植物正在逐渐减少或者已经丧失, 其中一个可能的原因是藻华暴发时,大面积藻华 覆盖于湖泊水体表层, 限制光线穿透水体, 从而对沉水植物产生抑制作用. 在贫痟的沉积物中, 反硝化速率 较低,这可能使得 $\mathrm{NO}_{3}^{-}$有保留在水体中的趋势, 从而有利于大型水生植物的吸收. 在天然湖泊中, 大型水生 植物的矿化过程需要很长的时间, 植物死亡后湖泊水体温度很低的情况下矿化过程所需的时间更长 ${ }^{[12]}$. 大型水生植物中 $\mathrm{C} / \mathrm{N}$ 比值较高 $(>20)$, 所以植物死亡后氮素可能主要是供给细菌生长, 故产生的 $\mathrm{NH}_{4}^{+}$量 相对较少. 大型水生植物是反硝化、亚硝化及氨化细菌的重要载体, 对微生物的分布影响较大. 王国祥 等 ${ }^{[16]}$ 测定了太湖人工生态系统中氮循环细菌的分布, 发现除硝化细菌外, 反硝化、亚硝化及氨化细菌均在 根际处最为密集, 且由根际向外呈现递减趋势. 用大型水生植物净化氮污染水体, 引入了量参与氮循环 的细菌, 并为氨化、硝化 - 反硝化过程创造了有利条件, 从而促进了水体氮素循环过程. 根据交替稳定态概 念, 沉水植物在生物操纵中的重要性得到越来越多的认可. 通过多种水生植物镶嵌组合的人工复合生态系 统对富营养化湖水进行治理 ${ }^{[17]}$,或使用固定化技术净化氮污染水体 ${ }^{[18]}$,都使水质得到了改善.

梅梁湾和东太湖分别是太湖具有代表性的藻型湖区和草型湖区. 2006 年 9 月,本实验室选择了东太湖 
和梅梁湾的底泥和水体构建微宇宙进行硝化 - 反硝化作用研究. 在黑暗条件下 $\left(22^{\circ} \mathrm{C}\right)$ 培养 $16 \mathrm{~d}$, 检测微宇 宙中 $\mathrm{NO}_{3}^{-} 、 \mathrm{NH}_{4}^{+}$和 $\mathrm{NO}_{2}^{-}$浓度的变化 (图 2). 对于藻型湖区, 实验初期泥与水构成的体系中进行的反硝化作 用强于硝化作用, $\mathrm{NO}_{3}^{-}$浓度降低而 $\mathrm{NH}_{4}^{+}$浓度没有显著变化; 实验后期体系中进行了剧烈的硝化作用, $\mathrm{NH}_{4}^{+}$ 浓度急剧降低而 $\mathrm{NO}_{3}^{-}$浓度上升. 藻型湖区只有湖水的微宇宙体系中, 总体上硝化作用强度大于反硝化作用 强度. 对于草型湖区, 在实验初期, 泥与水构成的微宇宙和只有湖水的微宇宙情况相似, 硝化作用强度较 大, 当 $\mathrm{NH}_{4}^{+}$浓度降低到一定数值之后硝化作用减缓. 实验进行第 $2 、 3 \mathrm{~d}$ 观察到草型湖区微宇宙中摇蚊幼虫 以及其他一些软体动物的死亡, 所以该体系在实验中期 $\mathrm{NH}_{4}^{+}$浓度略微上升的原因可能是生物体的死亡分 解. 实验后期,泥与水构成的微宇宙硝化作用强于反硝化作用, 出现了 $\mathrm{NO}_{3}^{-}$的累积. 从图 2 还可以观察到, 在 $\mathrm{NH}_{4}^{+}$浓度急剧下降的时间段内, $\mathrm{NO}_{2}^{-}$浓度出现峰值, 可推断强烈的硝化作用是 $\mathrm{NO}_{2}^{-}$累积的主要原因. Pauer ${ }^{[19]}$ 等的研究认为, 硝化作用主要在沉积物表面进行, 水体中的硝化速率相当低, 接近于零. 本实验中 发现, 在太湖藻型湖区和草型湖区的沉积物和水体中都进行了剧烈的硝化作用, 且藻型湖区的硝化作用进 行程度强于草型湖区. 湖泊的营养状态影响其生态结构; 食物链中的生态群落组成同样也会影响氮素的生 物地球化学循环. 本实验中藻型湖区的营养水平异于草型湖区, 其相对应的微生物生态结构的差异性必然 会影响硝化作用、反硝化作用等进程.
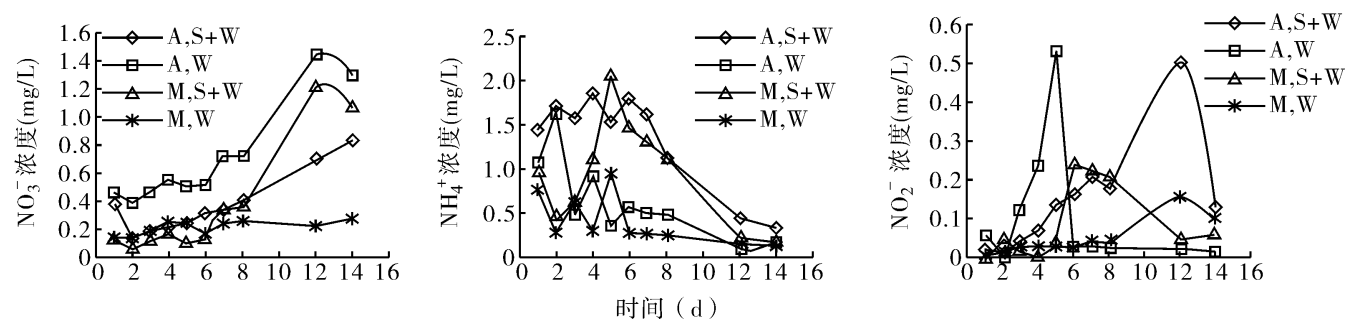

图 2 微宇宙实验中草型湖区和藻型湖区 $\mathrm{NO}_{3}^{-} 、 \mathrm{NH}_{4}^{+}$和 $\mathrm{NO}_{2}^{-}$浓度的变化 $(A, S+W$ : 藻型湖区, 沉积物 + 湖水; $A, W$ : 藻型湖区, 湖水; $\mathrm{M}, \mathrm{S}+\mathrm{W}$ : 草型湖区, 沉积物 + 湖水; $\mathrm{M}, \mathrm{W}$ : 草型湖区, 湖水)

Fig. 2 The change of $\mathrm{NO}_{3}^{-} 、 \mathrm{NH}_{4}^{+}$and $\mathrm{NH}_{4}^{+}$in macrophytic/algal lake in microcosms $(\mathrm{A}, \mathrm{S}+\mathrm{W}$ : Algal lake, Sediments + Water; A, W : Algal lake, Water; $\mathrm{M}, \mathrm{S}+\mathrm{W}:$ Macrophytic lake, Sediments + Water; M, W : Macrophytic lake, Water)

\section{4 湖泊氮素的生物地球化学循环中微生物参与的重要过程}

在氮素的生物地球化学循环过程中,生物转化比非生物转化更重要. 微生物是氮循环的驱动洜, 一方 面使氮循环不被中断, 另一方面维持生态系统的氮素平衡. 在没有人为活动干扰的湖泊中, 微生物在氮素 的输人和向大气释放过程中起着非常重要的作用 ${ }^{[20]}$.

微生物驱动的氮循环不是孤立的, 而是与 $\mathrm{C} 、 \mathrm{O} 、 \mathrm{~S} 、 \mathrm{P}$ 等营养元素的循环密切相关, 并受多种金属以及有 机化学物质所影响 ${ }^{[20]}$. 氮循环中许多氧化还原反应是在微生物的新陈代谢过程中进行的, 特定的酶对这 些反应具有催化作用. 因此, 研究氮循环中的微生物过程时, 酶和相对应的基因是研究的重要目标. 氮循环 中的重要过程及其对应的微生物和酶的研究成果已有报道 ${ }^{[21-23]}$.

1.4.1 硝化作用 硝化作用分两个步骤进行, 至今没发现能够直接将 $\mathrm{NH}_{4}^{+}$氧化成为 $\mathrm{NO}_{3}^{-}$的微生物 ${ }^{[24]}$. 硝 化作用是需氧反应, 溶解氧 ( DO) 不足, 微生物的繁殖和硝化活性等受到制约 ${ }^{[25]}$. 低氧浓度下, 部分硝化细 菌能参与反硝化作用, 对 $\mathrm{N}_{2} \mathrm{O}$ 和 $\mathrm{N}_{2}$ 的产生有重要贡献 ${ }^{[21]}$. 湖泊中硝化作用最重要和最强烈的地点是有氧 沉积物, 原因是沉积物上表层存在大量的硝化细菌 ${ }^{[19]}$. 但是在 $\mathrm{NH}_{4}^{+}$浓度较高的富营养化湖泊水体中, 同样 也具有较高的硝化速率. 硝化作用与湖泊水体营养状态密切相关.

1.4 .2 反硝化作用 反硝化是厌氧反应, 只有当氧气浓度足够低时才会发生, 但并不是氧的分压越低越好, 而应保持一定的含氧量 ${ }^{[25]}$. 反硝化速率依赖于上覆水中 $\mathrm{NO}_{3}^{-}$的浓度, 上覆水中 $\mathrm{NO}_{3}^{-}$浓度越高反硝化速率 
越大. $\mathrm{pH}$ 在自然范围内 ( $\mathrm{pH}$ 为 4-9) 对反硝化几乎没有影响; 湖泊沉积物层厚度的不均匀性对反硝化速率 的影响不大 ${ }^{[6]}$. 而有机质含量和温度都对反硝化有很大的影响, 增加有机质含量或者提高温度, 反硝化作 用增强; 但是当温度或有机质含量增到一定程度后, 没有或者只有很少程度的反硝化过程发生,这可能是由 于更多的氧被矿化过程和 $\mathrm{CH}_{4}$ 氧化过程所消耗 ${ }^{[26]}$.

反硝化作用在湖泊生态系统中具有重要生态意义. 然而反硝化细菌生长缓慢, 反硝化速率较低, 所以 在富营养化湖泊治理过程中反硝化过程的控制存在较大的难度.

目前已有的研究表明, 反硝化作用主要在沉积物中进行, 通过沉积物厌氧层内的反硝化作用, 以 $\mathrm{N}_{2} \mathrm{O}$ 、 $\mathrm{N}_{2}$ 等气体形态去除的内源氮负荷, 可达到湖泊外源性氮输人总量的一半以上. 然而在藻华暴发的水体中, 除了沉积物进行反硝化作用外, 藻才内形成的好氧 - 缺氧的微环境, 以及蓝藻衰亡过程中的分解产生大量 的有机物, 加剧水体中溶解氧的消耗, 导致水体中氧化还原电位大幅度下降. 较低的氧化还原电位, 将有利 于微生物反硝化作用的进行, 使水体中氮素赋存数量降低. 所以,对蓝藻水华暴发和衰亡过程中硝化和反硝 化能力的定量研究,将可以阐明藻华暴发对水体氮素迁移转化的影响.

1.4 .3 固氮作用 在不受人为干扰的自然界中,生物固氮是补偿反硝化导致氮素输出的唯一途径; 但是对 于氮污染严重的富营养化湖泊来说, 生物固氮是可以忽略的 ${ }^{[27]}$. 迄今为止, 只发现了少数的几类细菌能将 大气中的 $\mathrm{N}_{2}$ 转化为生物可利用氮 ${ }^{[22]}$. 在湖泊生态系统中, 蓝细菌是重要的固氮浮游生物; 沉积物中的部分 异养细菌是重要的固氮菌.

1.4 .4 厌氧氨氧化 厌氧氨氧化首先是在废水处理厂的生物反应器中发现的, 在此之前人们一直认为反硝 化是水生态系统中 $\mathrm{N}_{2}$ 产生和沉积物中氮素去除的唯一方式. 以前的研究认为, 在厌氧条件下, 微生物以 $\mathrm{NO}_{3}^{-}$为电子受体, 以 $\mathrm{NH}_{4}^{+}$为电子供体进行反应产生 $\mathrm{N}_{2}$, 现研究发现反应中接受电子的是 $\mathrm{NO}_{2}^{-}$而不是 $\mathrm{NO}_{3}^{-[28]}$. 目前, 厌氧氨氧化是海洋环境中研究的热点, Schubert ${ }^{[29]}$ 等首先在湖泊生态系统中发现了该过程.

目前对于影响厌氧氨氧化的环境因素的了解还很少, 沉积物矿化速率是最重要的因素, 其次是 $\mathrm{NO}_{3}^{-}$ 浓度、有机质含量、厌氧氨氧化菌的生长状况等. 在厌氧沉积物中, 厌氧氨氧化依赖于 $\mathrm{NO}_{3}^{-}$还原为 $\mathrm{NO}_{2}^{-}$的 过程, 但是并不受该过程的限制. 当 $\mathrm{NH}_{4}^{+}$浓度较低时, 厌氧氨氧化菌将与硝化细菌以及同化吸收 $\mathrm{NH}_{4}^{+}$的藻 类共同竞争 $\mathrm{NH}_{4}^{+}$, 所以厌氧氨氧化过程可能会受到限制. 厌氧氨氧化的绝对速率与水深并不相关, 尽管其 在浅水中趋于有更高的速率. 与反硝化作用相比, 浅水中厌氧氨氧化对氮素的去除所占比重较小, 但深水 中情况刚好相反 ${ }^{[30]}$.

废水处理厂中的厌氧氨氧化过程似乎只发生在严格厌氧的条件下,但自然环境中厌氧氨氧化菌株可能 对 $\mathrm{O}_{2}$ 具有更高的耐受性. 在海洋中, 厌氧氨氧化对氮素的去除能力不稳定: 有时产生的 $\mathrm{N}_{2}$ 占 $\mathrm{N}_{2}$ 总产生量 的 $60 \%$ 以上; 有时又没有检测出厌氧氨氧化活性 ${ }^{[30]}$. 在湖泊中, 厌氧氨氧化方面的研究还很少. 由于海洋 和湖泊存在一定的相似性, 而且厌氧氨氧化菌可能会随环境变化而进行变异, 所以在高浓度 $\mathrm{NH}_{4}^{+}$和厌氧环 境普遍存在的富营养化湖泊中, 厌氧氨氧化过程是否同样具有十分重要的作用,这些问题需要进一步研究.

\section{2 主要研究方法}

\section{1 同位素标记 ${ }^{15} \mathrm{~N}$ 示踪技术}

湖泊生态系统中的研究可以借助其他生态系统的研究手段. 目前, 同位素标记 ${ }^{15} \mathrm{~N}$ 技术已经广泛运用 于跟踪各种生态环境中氮素的迁移、滞留和转化 ${ }^{[22]} \cdot{ }^{15} \mathrm{~N}$ 标记的化合物可计算氮素在食物网中进行的迁移 和转化速率 ${ }^{[31]}$ 、测定硝化速率等. Trimmer 和 Kuypers 等使用 ${ }^{15} \mathrm{~N}$ 标记的化合物证明了废水处理厂和海洋中 存在厌氧氨氧化过程 ${ }^{[4,28]}$.

\section{2 分子生物学技术}

参与氮循环的微生物只有小部分可进行培养分离, 大部分微生物生长缓慢且无法获得纯培养物, 所以 使用传统的显微技术和微生物学方法来识别和描述湖泊氮循环相关的微生物受到了很大限制. 随着现代 分子生物学的发展, 各种分子生物学工具越来越广泛地应用于微生物群落结构和功能的研究, 使得人们能 够突破这些限制, 在基因水平研究微生物的群落结构以及环境变化所带来的影响. 16S rRNA 序列分析 ${ }^{[21]}$,

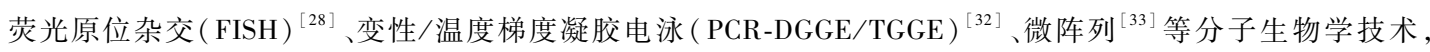


显著扩展了人们对氮循环微生物的认识以及对其多样性的了解.

\section{3 建立人工生态系统}

为了便于控制实验条件,建立人工生态系统如中宇宙、微宇宙等来模拟自然界中氮素的迁移转化,还可 以与微型传感器等其他技术联用来检测氮素流通量 ${ }^{[34,35]}$. 对于氮素循环很多的理解来自于废水处理系统 和实验室, 实验室环境与自然环境存在差异, 将实验室获得的各种结论外推到湖泊生态系统时会产生不确 定性,需要结合实际情况进行客观深人的分析和比较.

\section{3 存在的问题和研究展望}

\section{1 存在的问题}

到目前为止,对湖泊中氮素生物地球化学循环的研究已经取得了一些成果,但同时也存在着很多难题. 湖泊氮素迁移转化过程中相互关联的各个过程构成了一个复杂开放的循环体系,不同的环境因子会影响反 应的具体过程,多个反应可以同时利用同一种氮素形态,沉积物 - 水体 - 大气三者界面不断进行交换的氮 素难以量化等等,这些都增加了研究的难度.

目前关于蓝藻水华生态学的研究主要集中于氮磷元素对蓝藻生长和繁殖的影响, 而在蓝藻水华生命周 期中蓝藻对水体中氮磷元素含量的反作用研究相对较少.

对于参与氮循环的一些特定菌种, 其生理学、生物化学以及分子调节机制方面已经进行了大量研究. 然而, 目前关于这些微生物生态学方面的知识还远远不够, 自然界中的微生物群落十分复杂和多样化, 那些 通过纯培养之后进行大量研究的细菌可能并不是自然界中最重要的反应参与者. 在复杂的微环境中, 已经 采用 PCR 的方法量化特定的基因,但是此技术在操作过程中非目的基因的非特异性扩增以及苂光探针与 DNA 的非特异性结合又成为了难题. 使用 DGGE/TGGE 等技术对于 DNA 的分离起到很大的帮助,但也不 能将全部的 DNA 分离出来进行克隆和测序. 特别是反硝化细菌的功能基因的难以确定性和相关酶的不稳 定性,使得反硝化过程更加难以分析透彻.

此外,随着生态系统、环境条件和人们的生产、生活方式的快速变化,湖泊氮素生物地球化学循环将受 到影响, 人们将面临一些新的问题如严重富营养化湖泊中氮素的处理、氮素循环相关微生物的形态和基因 变异等等.

国内对湖泊生态的研究是比较全面的,但是氮循环方面的研究还不多,对湖泊中氮循环相关微生物的 群落结构和生态功能以及遗传学特性研究得更少. 氮素循环与湖泊的营养状况密切相关, 我国湖泊普遍面 临着富营养化问题,这要求我国在湖泊氮循环方面应加大研究力度.

\section{2 研究展望}

随着理论研究的深人,人们对于湖泊氮素生物地球化学循环的各个过程的认识正在逐步加深,硝化、反 硝化、固氮作用等方面的研究已经从理化影响因子深人到了参与该过程的酶及其对应的基因序列.

对于富含 $\mathrm{NH}_{4}^{+}$的富营养化湖泊,通过硝化作用使 $\mathrm{NH}_{4}^{+}$向 $\mathrm{NO}_{3}^{-}$转变, 以利于大型水生植物同化吸收,使 得湖泊由藻型浊水状态向草型清水状态转化. 蓝藻水华的暴发对氮转化的生态效应和对湖泊自我生态恢 复能力有何影响, 同时, 富营养化湖泊中厌氧环境普遍存在, 厌氧氨氧化可能是去除 $\mathrm{NH}_{4}^{+}$的一个重要途径. 这些是目前需要进一步探讨的问题.

分子技术是研究自然环境中微生物的强有力的工具,特别是对于那些不可培养的微生物. 对于参与湖 泊氮素循环的各种微生物, 需要开发和借助更加完善的分析技术和工具, 解决厌氧氨氧化菌难以培养分离, 部分酶难以检测和纯化等问题. 从分子生物学水平掌握微生物的氮代谢途径: 获得相关的基因序列, 明确 相关的基因的功能,利用基因芯片技术来检测湖泊生态系统中细菌的分布及其代谢状况.

将宏观的湖泊富营养化治理与微观的微生物氮代谢过程结合起来,将传统的生物化学、生态学与现代 基因组学、分子生物学研究结合在一起,加快对湖泊氮素生物地球化学循环过程的了解,同时推动湖泊氮污 染控制的进程.

\section{4 参考文献}

[1] Galloway J N, Bekunda M, Cai Z et al. A preliminary assessment of "Changes in the global nitrogen cycle as 
a result of anthropogenic influences". Third International Nitrogen Conference, Nanjing, China: October 2004.

[2] 孔繁翔,高 光. 大型浅水富营养化湖泊中蓝藻水华形成机理的思考. 生态学报,2005,25 (3):589 $-594$.

[3] 杨柳燕, 肖 琳. 环境微生物技术. 北京:科学出版社, 2003:83-87.

[4] Trimmer M, Nicholls J C, Deflandre B. Anaerobic Ammonium Oxidation Measured in Sediments along the Thames Estuary, United Kingdom. Applied and Environmental Microbiology,2003,69( 11 ):6447 - 6454 .

[5] Zehr J P, Ward B B. Nitrogen Cycling in the Ocean: New Perspectives on Processes and Paradigms. Applied and Environmental Microbiology,2002,68(3) :1015 - 1024.

[6] Jeff M, John W M. Ammonium release from resuspended sediments in the Laguna Madre estuary. Marine Chemistry, $1999, \mathbf{6 5}(1 / 2): 97-110$.

[7] 全为民,严力蛟. 农业面源污染对水体富营养化的影响及其防治措施. 生态学报,2002,22(3):291 -299 .

[8] 宋玉芝,秦伯强,杨龙元等. 大气湿沉降向太湖水生生态系统输送氮的初步估算. 湖泊科学, 2005, 17 ( 3 ) : $226-230$.

[9] Nydick K R, Lafrancois B M, Baron J S et al. Lake-specific responses to elevated atmospheric nitrogen deposition in the Colorado Rocky Mountains, USA. Hydrobiologia,2003,510:103 - 114 .

[10] 秦伯强,范成新. 大型浅水湖泊内源营养盐释放的概念性模式探讨. 中国环境科学,2002,22 (2) : 150 -153 .

[11] 范成新, 相崎守弘. 好氧和厌氧条件对霞浦湖沉积物 - 水界面氮磷交换的影响. 湖泊科学, 1997,9 (4) $: 337-342$.

[12] Golterman H L. The Chemistry of Phosphate and Nitrogen Compounds in Sediments. Dordrecht/Boston/London: Kluwer Academic Publishers, 2004 : 135 - 180.

[13] Postolache C, Rî̌nnoveanu G, Vãdineanu A. Nitrogen and phosphorous excretion rates by tubificids from the Prahova River ( Romania). Hydrobiologia,2006,553:121 - 127.

[14] Gu B H, Alexander V. Dissolved Nitrogen Uptake by a Cyanobacterial Bloom ( Anabaena flos-aquae) in a Subarctic Lake. Applied and Environmental Microbiology,1993,59(2):422 - 430 .

[15] 刘春光,邱金泉,王 雯等. 富营养化湖泊治理中的生物操纵理论. 农业环境科学学报,2004,23 ( 1$)$ : $198-201$.

[16] 王国祥, 兴培民, 黄宜凯等.太湖人工生态系统中氮循环细菌分布. 湖泊科学, 1999,11(2):160 - 164.

[17] 王国祥,誉培民, 张圣照. 人工复合生态系统对太湖局部水域水质的净化作用. 中国环境科学, 1998, $\mathbf{1 8}(5): 410-414$.

[18] 李正鬼,泆培民. 净化湖泊水体氮污染的固定化硝化 - 反硝化菌研究. 湖泊科学, 2000,12(2) : 119 -123 .

[19] Pauer J J,Auer M T. Nitrification in the water column and sediment of a hypereutrophic lake and adjoining river system. Water Research,2000,34(4):1247 - 1254 .

[20] 李思亮, 刘丛强, 肖化云. 地表环境氮循环过程中微生物作用及同位素分馏研究综述. 地质地球化学, $2002, \mathbf{3 0}(4): 40-45$.

[21] Jetten M S M, Logemann S, Muyzer G et al. Novel principles in the microbial conversion of nitrogen compounds. Antonie van Leeuwenhoek, 1997,71:75 - 93 .

[22] Zehr J P, Carpenter E J, Villareal T A. New perspectives on nitrogen-fixing microorganisms in tropical and subtropical oceans. Trends in Microbiology,2000,8(2):68-73

[23] Casciotti K L, Ward B B. Dissimilatory nitrite reductase genes from autotrophic ammonia-oxidizing bacteria. Applied and Environmental Microbiology,2001,67 ( 5 ) :2213 - 2221. 
[24] Van Loosdrecht M C M, Jetten M S M. Microbiological conversions in nitrogen removal. Water Science and Technology, 1998,38(1):1-7.

[25] Martin T L, Kaushik N K, Trevors J T et al. Review : denitrification in temperate climate riparian zones. Water, Air , and Soil Pollution,1999,111 (1/4):171 - 186.

[26] Luijn F V, Boers P C M, Lijklema L et al. Nitrogen fluxes and processes in sandy and muddy sediments from a shallow eutrophic lake. Water Research,1999,33(1):33 - 42 .

[27] Tõnno I, Ott K, Nõges T. Nitrogen dynamics in the steeply stratified, temperate lake Verevi, Estonia. Hydrobiologia,2005,547:63 - 71.

[28] Kuypers M M M, Sliekers A O, Lavik G et al. Anaerobic ammonium oxidation by anammox bacteria in the Black Sea. Nature,2003,422:608 - 611.

[29] Schubert C J, Durisch-Kaiser E, Wehrli B et al. Anaerobic ammonium oxidation in a tropical freshwater system (Lake Tanganyika). Environmental Microbiology,2006,8(10):1875 - 1863.

[30] Dalsgaard T, Thamdrup B, Canfield D E. Anaerobic ammonium oxidation (anammox) in the marine environment. Research in Microbiology,2005,156:457 - 464.

[31] Dodds W K, Evans-White M A,Gerlanc N M et al. Quantification of the nitrogen cycle in a Prairie stream. Ecosystems, $2000,3: 574-589$.

[32] Oved T, Shaviv A, Goldrath T et al. Influence of Effluent Irrigation on Community Composition and Function of Ammonia-Oxidizing Bacteria in Soil. Applied and Environmental Microbiology,2001,67 (8) :3426 - 3433.

[33] Taroncher-Oldenburg G, Grimer E M,Francis C A et al. Oligonucleotide Microarray for the Study of Functional Gene Diversity in the Nitrogen Cycle in the Environment. Applied and Environmental Microbiology, $2003, \mathbf{6 9}(2): 1159-1171$.

[34] Gardner W S, Nalepa T F, Malczyk J M. Nitrogen mineralization and denitrification in lake Michigan sediments. Limnology and Oceanography, 1987,32(6) : 1226 - 1238.

[35] Stief P, Schramm A, Altmann D et al. Temporal variation of nitrification rates in experimental freshwater sediments enriched with ammonia or nitrite. FEMS Microbiology Ecology,2003,46:63-71. 